\title{
The Relief-Reconstruction-Development Dynamic: A New Approach to the Concept of Linking Relief, Reconstruction, and Development
}

\author{
Paul Spiegel
}

\begin{abstract}
After a critical analysis of the relief-development continuum, a new conceptual model is proposed for areas with chronic instability in complex humanitarian emergencies-the Relief-Reconstruction-Development Dynamic (R2D2). This model incorporates the dynamic interactions of the relief, reconstruction and development phases over time and geography. Using the chronic instability of Liberia between 1990 and 1997 as an example, the author applies the R2D2 model. Liberia is divided into "maximal geographic units" and a conflict scale is applied. The resulting graph shows varying degrees of conflict between different regions which varied independently over time. Situations of chronic instability do not follow a linear pattern but instead, form a complex interactive dynamic of phases which varies over time and geography. Donoragencies and nongovernmental organizations should recognize this dynamic process and consequently fund and design programs which more appropriately address the different needs of areas within a situation of chronic instability over time.
\end{abstract}

\section{Précis}

Après uneanalysecritiquedu continuum de développement de l'assistance aux réfugiés, un nouveau modèle conceptuel est proposé pour les urgences humanitaires complexes en zones d̀ instabilité chronique: la Dynamique Assistance-Reconstruction-Développement (ReliefReconstruction-Development Dynamic-R2D2). Ce modele incorpore les interactions dynamiques entre l'assistance et les phases de reconstructionet de développement dans le temps et

Paul B. Spiegel, M.D., M.P.H., is an Assistant Scientist in the Department of International Heal th at the Johns Hopkins School of Hygiene and Public Health, Baltimore, Maryland, United States. la géographie. L'auteur applique le modele R2D2 à l'exemple de l'instabilité chronique du Liberia entre 1990 et 1997. Le Liberia est subdivisé en «unités géographiques maximales», et une échelle conflictuelle est appliquée. Le modèle résultant montre des degrés variables de conflits entre différentes régions, ayant varié de façon indépendante au cours $d u$ temps. Les situations d' instabilité chronique ne suivent pas un modèle linéaire mais plutôt forment une dynamique complexe de phases en interaction variant selon le temps et la géographie. Les organismes donateurs et les organisations non gouvernementales devraient reconnaître ce processus dynamique et conséquemment financer des programmes qui prennent plus adéquatement en compte les besoins variables des zones impliquées dans une situation d'instabilité chronique se déployant dans le temps.

\section{Introduction}

For decades, relief and development have been considered as separate entities. Expertise has developed in both fields, but it is uncommon to find organizations which concentrate upon both disciplines. Even when organizations claim to be specialists in both disasters and development, they are often thwarted by funding agencies, which will fund projects for relief, or projects for development, but rarely at the same time and in the same situation. Relief, reconstruction and development have been considered a linear spectrum, one phase inexorably leading to the next over time. During the pastdecade, many people and organizations have called for development programs to be implemented as soon as possible after an emergency occurs, a so-called "developmental relief." ${ }^{1}$ Numerous examples of implementation of some parts of developmental programs havebeen cited, ${ }^{2}$ but an overall model has not yet been suggested. In this paper, definitions will be discussed together with their limitations, old models will be critically analyzed and a new model will be proposed, using data from a case study of Liberia.

\section{Definitions}

Relief

Relief is defined as the action taken to reduce suffering and save lives. ${ }^{3}$ This action is aimed at saving the greatest number of victims in a limited time by reducing life-threatening conditions and helping only those affected by the emergency.

This definitionignores the concept of sustainability and different magnitudes of emergencies (at one point in time as well as geographically).

\section{Reconstruction}

Reconstruction is the action taken to recover and reconstruct a system or infrastructure which existed prior to an emergency.

The definition is usually used as a term in between the linear spectrum of relief and development. Reconstruction should be seen as an opportunity for change. It should not be interpreted literally (i.e., to "reconstruct" the previous system), but used as an opportunity to construct a system or infrastructure using the positive aspects of the previous system while attempting to correct its past deficiencies. Thus the reconstruction phase should be interpreted as a reconstruction and construction phase or a "(re)construction plus" phase.

\section{Development}

Development is the process of bringing about sustainable improvement in socioeconomic and health conditions. ${ }^{4}$

Development is usually assumed to be the final phase in a linear model and is considered to occur over many years after relief and reconstruction. In fact,

Refuge, Vol.17, No. 4 (October 1998) 
development should be incorporated into all stages: before, during and after an emergency, in different degrees and with different emphases.

\section{The Relief-Development Continuum Model}

When a disaster occurs, attention is immediately focused on relief efforts to help the country and people recover from the crisis. Usually, whatever development activities which were occurring at the time are suspended, and the development workers either leave the country or allow the relief workers to take over. A crisis attracts media attention which, in turn, attracts donors and money. However, the funds are generally restricted to relief efforts. As the crisis ameliorates, reconstruction begins. Money is once again usually earmarked for reconstruction. Finally, development begins after reconstruction phase.
The development experts return to the country and attempt to take over from where they left off. There is overlap between these three phases, but in general, one phase predominates throughout the whole country at one time our (see figure 1). ${ }^{5}$

\section{Problems with Relief-Development Continuum (RDC)}

The RDC is a linear concept which assumes that the phases occur in order with little interaction. Created for a natural disaster scenario, the RDC assumes that the pre-disaster situation was stable and that development was taking place. This linear model is not appropriate for situations of chronic instability (i.e., Liberia, Somalia, Angola, etc.). ${ }^{6}$ Instead, such situations require a more dynamic model where phases can change from one to either of the other two as well as occur simulta- neously within same geographic area or between areas.

\section{Dynamic between Relief, Reconstruction, and Development}

Relief, reconstruction, and development are notmutually exclusive phases nor should they be thought of in a linear fashion. They exist within a spectrum, in which they can shift or change from one to either of the other two as well as occur simultaneously within same geographic area or between areas (see figure 2).

\section{Relief-Reconstruction-}

Development-Dynamic (R2D2)

\section{Mode}

The R2D2 model should be thought of as interactive and dynamic with respect to both time and geography, rather than a linear continuum.

Figure 1: The Relief-Development Continuum (RDC)

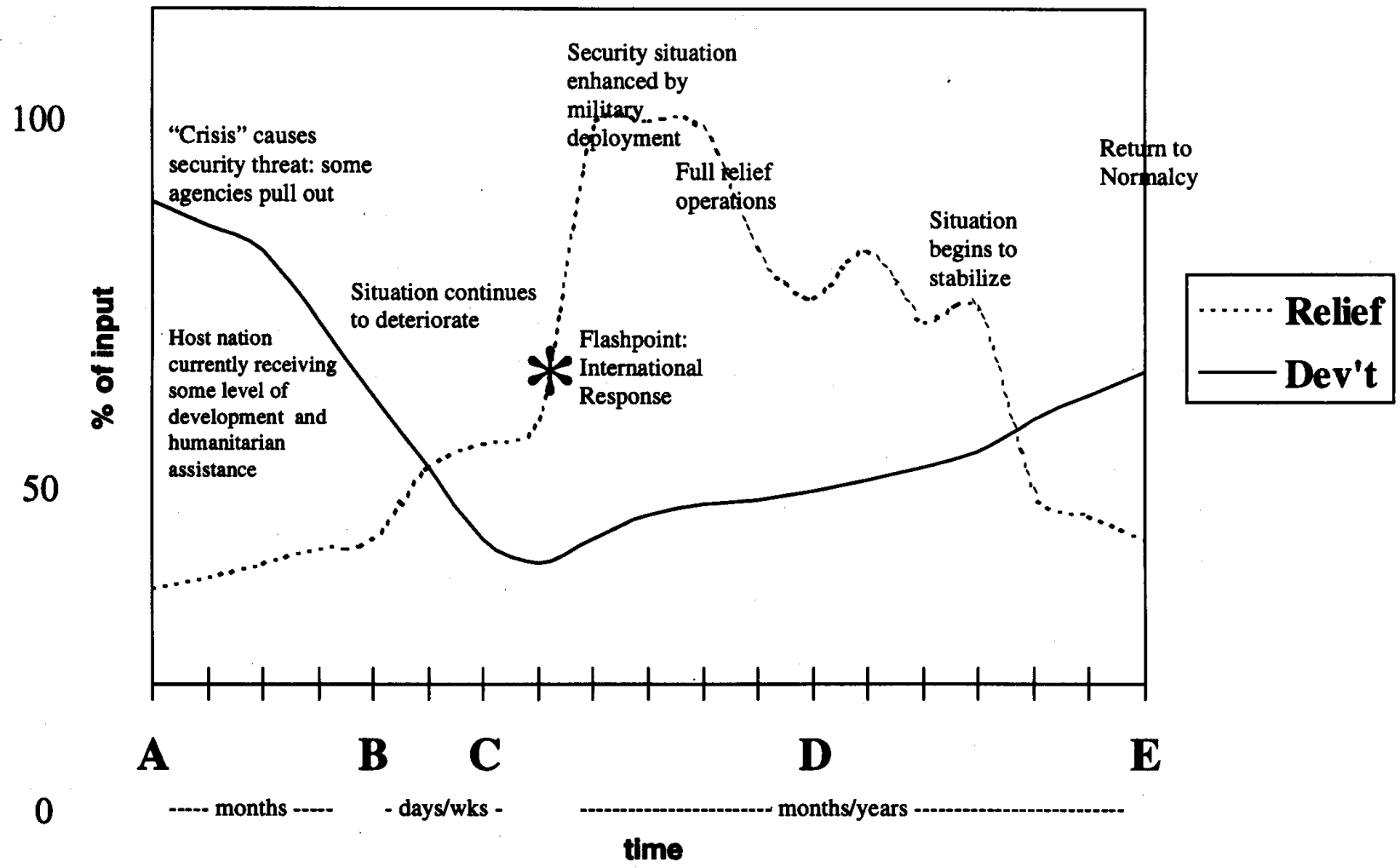


Figure 2: Interactions between Relief, Reconstruction, and Development: Dynamic versus Linear

Dynamic

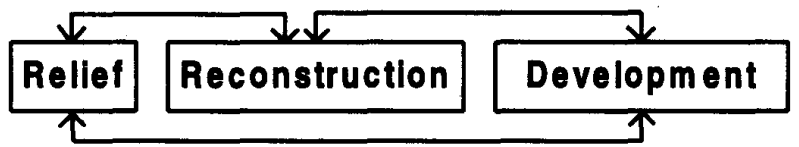

Linear

\section{Relief $\rightarrow$ Reconstruction Development}

Figure 3: R2D2 Model as Applied to Liberia between 1990 and 1997

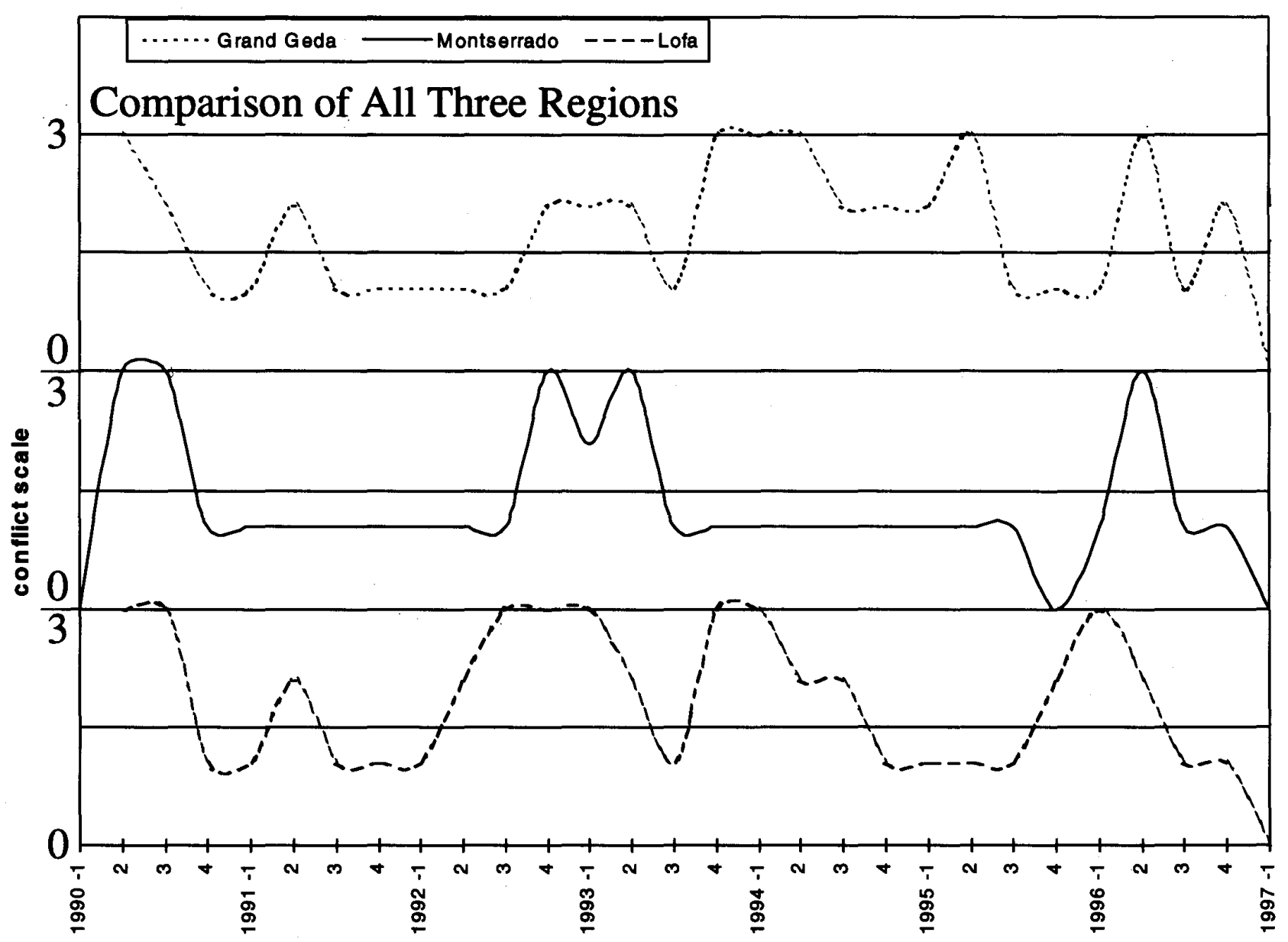

\section{Conflict Scale}

3 - open and widespread warfare, evacuation of expatriate personnel from NGOs, UN, Embassy staff, local population fleeing the area.

2-heightened insecurity amongst the local population (ie increased number of soldiers and people with guns in the streets, local food staples increase in price, people begin to hoard food.

1-limited security (ie stable population, repatriation occurring, limited economic activity).

0 -ceasefire-normal activity begins to return to the community. 
The $x$-axis will generally be used for time, while the $y$-axis can be used for numerous categories, some of which include:

i. malnutrition rates,

ii. disease-specific morbidity rates, iii. economic indicators (i.e., GDP),

iv. water/sanitation indicators (i.e., $x$ liters/person/day),

v. mortality rates,

vi. population shifts, and

vii. conflict scale.

The graphs can be plotted in numerous different fashions depending upon the axes and the concept one is attempting to describe. The following types of graphs could be used:

i. linearly over time (see figure 3),

ii. point prevalence (i.e., Department of Humanitarian Assistance's joint riskmapping), ${ }^{7}$

iii. overlay 1 or more categories on top of each other, and

iv. 3-dimensional graphs using 2 categories which were shown to be statistically unrelated.

\section{Applying the R2D2 Model}

The area of chronic instability (i.e., a country) should be divided into sections, using the largest geographical area possible (i.e., city, county, district, province, etc.). This designated "maximal geographic unit" should have relatively similar conditions and should be labelled with the most appropriate phase (relief, reconstruction, development). Then, specific interventions should be planned and implemented accordingly. The situation needs to be re-evaluated periodically, with respect to the geographic divisions as well as the applicable phase, and changes made according to the past and present situation.

\section{Background to the Liberian Conflict}

Liberia's seven-year civil war started in December 1989 . Shortly after it began, the uprising spread quickly to most parts of the country. The subsequent factionalization of the conflict (10 warring factions) contributed significantly to the war's prolongation, causing a serious and chronic humanitarian crisis. $^{8}$

The protracted civil war disrupted of economic and commercial activities, which resulted in the loss of livelihood for whole communities. Wide spread destruction or decay of public and private property and physical and social infrastructure also occurred. There were massive population movements and tremendous human suffering. One half of Liberia's 2.5 million pre-war population was internally or externally displaced and more than 150,000 people were killed. ${ }^{9}$

The factionalization of the conflict made it very difficult to secure peace. Numerous peace accords were broken (a total of 6 peace accords were signed between 1990 and 1997). ${ }^{10}$ As can be seen in figure 3 , the amount of conflict varied at different times throughout the war and was geographically dependent. The three largest battles occurred at the beginning of the war (December 1989), during Operation Octopus (late 1992/early 1993), and during the April 1996 crisis.

Figure 3, shows the R2D2 model applied to Liberia between 1990 to 1997.11 The $x$-axis represents time in years, while the y-axis represents conflict occurring in specific regions of Liberia (conflict scale is zero to three). Originally the maximal geographical unit chosen was the county. Each county within each of the three regions of Liberia were similar to each other, thus the maximal geographic unit was enlarged to regions. Grand Geda county represents the South-East region of Liberia, Montserrado county (which includes the capital Monrovia) the Central, and Lofa county the North-West.

\section{Application of the R2D2 Model to Liberia between 1990 and 1997}

Figure 3 shows regions with varying levels of conflict over time. The levels of conflict are often different between the three regions. For example, during the second quarter of 1991, Montserrado region was relatively calm while Grand Geda and Lofa regions had heightened security problems. A similar situation occurred in the fourth quarter of 1993.
One can observe many other differences between the regions as well as over time.

Regardless of the level of conflict occurring in each of the regions, the implementing non-governmental organizations (NGOs) considered all of Liberia to be in a state of emergency between 1990 and 1997. TheseNGOs were not only restricted in their program implementation due to their own methods of analyzing the situation but also because donors often restricted the way the money they granted could be spent. Many of the funding agencies insisted that the funds be spent only on emergency programs. Figure 3 portrays the dynamism between the three phases and shows the possibility of conducting different programs spanning all three phases in certain regions at certain times.

\section{Conclusion}

Donor agencies and NGOs should not view emergencies as being uniform throughout a country and having a linear progression over time. Recognition of the dynamic processes of chronically unstable situations in complex humanitarian emergencies is necessary if NGOs are to respond appropriately. By employing the R2D2 model in an area of chronic instability, NGOs may apply appropriate interventions to the corresponding maximal geographic units. Thus developmental programs may be appropriate in one province at a particular time, while emergency activities may be reasonable in another. These dynamic phases should be re-evaluated continuously throughout the period of instability to allow for modification of programs according to the evolving situation.

\section{Notes}

1. C. Lindahl, "Developmental Relief?: An Issues Paper and an Annotated Bibliography on Linking Relief and Development," Swedish International Development Corporation Agency (SIDA), March 1993.

2. M.Anderson and E. Hawksley, "Reducing Vulnerability to Drought and Famine: Developmental Approaches to Relief," Disasters 15, no. 1 (1989): 43-54. F. Cuny, Disasters and Development (New York: Oxford University Press, 1983). 
3. World Health Organization (WHO) "Hea1thin Relief and Development: A Strategic Framework for Emergency and Postcrisis Needs," World Health Organization, Division of Emergency and Humanitarian Action, draft 10, June 291998.

4. Ibid.

5. M. VanRooyen, "International Humani

tarian Assistance: Challenges for Health Workers Abroad," unpublished lecture at Johns Hopkins School of Hygiene and Public Health, February 1998.

6. I prefer to use the term chronic instability rather than chronic crisis, which connotes chronic emergency, thus implying relief as the dominant phase

7. United Nations Department of Humanitarian Affairs, "Joint Risk Mapping Project: Handover Report," Humanitarian Coordination Office in Liberia, Decembe $10,1997$.

8. World Health Organization (WHO), "Complex Emergency: The Liberian Experience-A Case Study of Liberia's Health Sector," World Health Organization, Division of Emergency and Humanitarian Action, midterm report, May 1998.

9. New African Research and Developmen Agency (NADRA), "A Report of the Round ( Directions for the Reconstruction and Development of Liberia," NADRA and the Ministry of Planning and Economic Affairs of Liberia, 1992.

10. A. Schowengerdt, P. Spiegel, and F. Spielberg, "Health Interventions in Complex Emergencies: A Case Study of Libeplex Emergencies: A Case Study of Libe-

11. Ibid. CI

\section{From Being Uprooted to Surviving: Resettlement of Vietnamese-Chinese JlBoafPeople" in Montreal, 1980..-1990 вy \\ Lawrence Lam}

Toronto: York Lanes Press; ISBN \},...55014-296-8, 200 pages, indexed

$$
\$ 18.95
$$

The. saga of the "boat people" is a. dramatic story,a. story of one of the largest refugee movements in recent. years. Ganada.played asignifitantrole in the resettlement of these refugees in bringing them to Canada where they could start anew. From Being Uprooted to Surviving by Professor Lam, is based on ethn<> graphic data of a sample of Vietnamt;se-Cbio.ese accepted for resettlementin Montreal in 1979 and 1980. who Were interviewed again in 198485 and in 1990-91, this book provides a longitudinal account of their experience of resettlement in Canada. This experience has been marked by sU essivestages of their struggle $\mathrm{t}()$ ovet; $<;<:>$ me structural barriers an, $\mathrm{d}$ to negotiate a meanIngful niche in Canada.

Contents; Preface. The Boat People Phenomenon, Resettlement-Issues and Perspectives. The Yietnamese-Cbinese. Refuge IExodusat1d Transit 011, Resettlement Process-The First Three Years. Resettlement-Beyond the First Three Years, Conclusion.

\section{Available from:}

Centre forJ.tefugee 5tUdiest York University

Suite 333. York Lanes, 4700 Keele Street

Toronto ON M3] 1P3

Fax: (416)736-5837 ...Email: (e£uge@yorku.c:a

\title{
Breaking Ground: The 1956 Hungarian Immigration to Canada Edited by Robert H. Keyserlingk
}

\author{
Toronto: York Lanes Press, 1993; ISBN 1-55014-232-1; 117
}

pages, $\$ 6.99$

This book isacollectic $>n$ of personal and archival-based memories on the selection,transportand settlement of about 40,000 Hungarian refugees in Canada in one year. It is a source of primary record as well as scholarly reflection on one of the most significant refugee movements to Canada after World War ll-the 1956 Hungarian refugee movement.

Based on papers that Were presented at a 1990 conference, the authors touch on the unique political, I administrative and settlement features of this movement. The resulting work, edited by Professor Keyserlingk, is a unique mix of personal reminiscences and academic scholarship.

$$
\sim \text {;()ailable from: }
$$

\section{Centre for Refugee Studies}

